\title{
PENINGKATAN AKTIVITAS SISWA MELALUI PEMBELAJARAN KOOPERATIF DISERTAI METODE OUTDOOR LEARNING PADA MATERI KELANGSUNGAN HIDUP DI KELAS IX A SMPN 1 SAMALANTAN
}

\author{
Suhaimi $^{1)}$, Yokhebed ${ }^{2)}$ \\ Guru Biologi SMPN 1 Samalantan ${ }^{1)}$ \\ Dosen Pendidikan Biologi FKIP Universitas Tanjungpura ${ }^{2)}$ \\ email: yokhebed0405@gmail.com
}

\begin{abstract}
This research was aimed to improve students' learning activities through cooperative learning model with outdoor learning method at viability organisms on IX A Junior Secondary School 01 Samalantan. Subjects in this study 33 students. The research instrument used is the observation sheet and field notes. Results showed that an increase in activity after the students are given cooperative learning model with outdoor learning method. Based on the analysis of data obtained the increased activity of the students at $72,73 \%$ after implementation cooperative learning model with outdoor learning method in two cycles of action.
\end{abstract}

Keywords: Students' activities, cooperative learning, outdoor learning method.

Proses pembelajaran IPA menurut Kurikulum Tingkat Satuan Pendidikan, menuntut kreativitas guru. Diantaranya adalah dalam memilih pendekatan dan model pembelajaran. Kegiatan pembelajaran yang diharapkan yaitu pembelajaran yang berpusat pada siswa. Siswa yang dituntut aktif dalam menemukan pengetahuan dan guru berperan membimbing dan membantu mereka. Guru memiliki keleluasaan dalam mengembangkan proses pembelajaran yang di sesuaikan dengan keadaan sekolah.Siswa dapat belajar di luar ruangan. Kegiatan di luar ruangan dapat menumbuhkan ketertarikan siswa. Diharapkan siswa aktif terlibat dalam belajar. Menurut Sardiman (dalam Sa'adah 2011) yang paling mendasar dalam proses pembelajaran adalah aktivitas siswa. Siswa yang aktif menyebabkan interaksi dengan antara guru dengan siswa tinggi. Sehingga, masing-masing siswa dapat mengembangkan kemampuannya semaksimal mungkin.

Observasi awal di kelas XI A SMPN 01 Samalantan, menemukan guru sangat dominan sehingga peserta didik pasif $(75 \%)$ siswa lebih banyak menunggu sajian materi dari guru dari pada menemukan sendiri. Siswa masih kesulitan dalam menemukan sendiri pengetahuan. Berdasarkan hal tersebut, diperlukan model dan metode pembelajaran yang dapat meningkatkan aktivitas siswa. Menurut Lie (2002) pembelajaraan kooperatif merupakan pembelajaran yang memberikan kesempatan kepada siswa untuk bekerja sama dengan sesama siswa lainnya dalam 
Tabel 1. Indikator aktivitas belajar siswa.

\begin{tabular}{cll}
\hline No & Indikator & \multicolumn{1}{c}{ Aspek yang diamati } \\
\hline 1 & $\begin{array}{l}\text { Aktivitas } \\
\text { menulis }\end{array}$ & $\begin{array}{l}\text { Mencatat hasil pengamatan } \\
\text { pada LKS }\end{array}$ \\
\hline & $\begin{array}{l}\text { Aktivitas } \\
\text { mental dan } \\
2\end{array}$ & $\begin{array}{l}\text { Melakukan pengamatan } \\
\text { Aktivitas } \\
\text { motorik }\end{array}$ \\
\hline & $\begin{array}{l}\text { Kegiatan } \\
\text { Lisan }\end{array}$ & $\begin{array}{l}\text { a. } \\
\text { b. } \begin{array}{l}\text { Mengajukan pertanyaan } \\
\text { Turut memberi komentar/ } \\
\text { pendapat atas jawaban } \\
\text { atau pertanyaan teman }\end{array}\end{array}$ \\
& &
\end{tabular}

2. Catatan Lapangan

Banyak aspek aktivitas yang diamati seperti suasana kelas, pengelolaan kelas, interaksi guru dan siswa, interaksi antar siswa dan antara siswa dengan guru. Keabsahan data dilakukan dengan teknik triangulasi. Data hasil lembar observasi dan catatan lapangan untuk aktivitas siswa dibandingkan dengan isi rekaman proses pembelajaran yang dilakukan oleh guru. Indikator kinerja penelitian ini terdiri atas peningkatan aktivitas siswa dan keterlaksanaan proses pembelajaran adalah aktivitas siswa jika jumlah siswa yang aktivitasnya baik dan sangat baik pada siklus II minimal $75 \%$, sedangkan proses pembelajaran terlaksana jika di atas $79 \%$.

Analisis data dilakukan melalui tiga tahap (Miles dan Huberman, 2009), yaitu: reduksi data, paparan data, dan penyimpulan. Penarikan kesimpulan tentang peningkatan atau perubahan yang terjadi dilakukan secara bertahap mulai dari kesimpulan sementara, yang ditarik pada akhir siklus I, ke kesimpulan yang telah revisi pada akhir siklus II. Data yang bersifat kuantitatif di analisis menggunakan rumus sebagai berikut ini:

Nilai Aktivitas

$=\frac{\text { Skor Aktivitas }}{\text { Skor Total Aktivitas }} \times 4$

Peserta didik memperoleh nilai:

Sangat Baik : 3,20 - 4,00 (80 - 100)

Baik : 2,80-3,19 $(70-79)$

Cukup : :2.40 - 2,79 (60-69)

Kurang : kurang 2.40 (kurang dari $60 \%)$.

Sumber: Kemendikbud (2013)

\section{Hasil dan Pembahasan}

1. Siklus 1

a. Perencanaan Siklus I

Perencanaan siklus 1 materi adaptasi morfologi, fisiologi dan tingkah laku. Kompetensi dasar pada pembelajaran ini mengidentifikasi kelangsungan hidup organisme melalui adaptasi, seleksi alam dan perkembangbiakan. Perencanaan tindakan pada siklus I mempersiapkan RPP model pembelajaran kooperatif dengan metode outdoor learning, serta menyusun lembar kerja siswa, lembar observasi aktivitas siswa dan lembar observasi guru.

b. Pelaksanaan Tindakan Siklus I Pelaksanaan tindakan dilakukan tanggal 13 September 2014 dalam 1 kali pertemuan selama $2 \times 40$ menit. Fase 1 menyampaikan tujuan dan memotivasi siswa. Guru menyampaikan salam dan mengatur tempat duduk siswa serta mengecek kehadiran siswa. Guru bertanya "Pernahkah kalian melihat daun keladi? Bagaimanakah bentuk daunnya? Mengapa demikian?" Selanjutnya, guru menyampaikan tujuan 
pembelajaran dan memotivasi siswa.

Fase 2 menyajikan informasi. Guru menyajikan informasi secara garis besar materi adaptasi pada makhluk hidup. Fase 3 mengorganisasikan siswa ke dalam kelompok belajar. Guru membentuk kelompok belajar yaitu 1 kelompok 4-5 orang. Selanjutnya, membagikan LKS untuk masing-masing kelompok. Fase 4 membimbing kelompok belajar. Guru mengajak siswa ke luar kelas (halaman sekolah dan sekitarnya) untuk melakukan pengamatan. Siswa melakukan pengamatan pada kolam dekat sekolah dan halaman sekolah. Siswa mengamati ciri hewan dan tumbuhan dan mengaitkannya dengan bentuk adaptasi makhluk hidup. Guru membimbing siswa mengerjakan LKS. Siswa mendiskusikan hasil pengamatan. Setelah selesai pengamatan siswa kembali ke kelas. Fase 5 evaluasi. Siswa menyampaikan / mempresentasikan hasil diskusi dan guru memberikan penguatan. Fase 6 memberikan penghargaan. Guru memberikan penghargaan melalui pujian atau tepuk tangan. Selanjutnya, dilakukan kegiatan penutup.

\section{c. Observasi Siklus I}

Pada proses pembelajaran berlangsung, pengamatan dilakukan oleh satu orang pengamat. Pengamatan dilakukan terhadap aktivitas siswa dan guru. Observasi aktivitas siswa pada siklus 1 sebesar $27,27 \%$. Jumlah siswa yang aktif belum mencapai indikator kinerja. Observasi aktivitas siswa per aspek, disajikan pada Tabel 2.

Tabel 2. Persentase aktivitas siswa siklus 1 .

\begin{tabular}{clc}
\hline No & $\begin{array}{l}\text { Aspek pengamatan } \\
\text { aktivitas }\end{array}$ & $\begin{array}{c}\text { Siklus 1 } \\
(\mathbf{\%})\end{array}$ \\
\hline 1 & $\begin{array}{l}\text { Mengajukan } \\
\text { pertanyaan }\end{array}$ & 24,24 \\
\hline & $\begin{array}{l}\text { Turut memberi } \\
\text { komentar/ pendapat } \\
\text { atas jawaban/ } \\
\text { pertanyaan teman }\end{array}$ & 24,24 \\
\hline 3 & $\begin{array}{l}\text { Mencatat hasil } \\
\text { pengamatan pada } \\
\text { LKS }\end{array}$ & 81,81 \\
\hline 4 & $\begin{array}{l}\text { Melakukan } \\
\text { pengamatan }\end{array}$ & 100 \\
\hline
\end{tabular}

Aktivitas tertinggi yaitu melakukan pengamatan sebesar $100 \%$, disusul dengan aktivitas mencatat hasil pengamatan $81,81 \%$.

d. Refleksi Siklus I

Pada pembelajaran menggunakan model kooperatif disertai metode outdoor learning pada Siklus I terdapat beberapa kekurangan. (1) Guru belum melakukan penguatan setelah siswa mempresentasikan hasil diskusi, (2) guru kesulitan memantau proses pembelajaran di luar kelas karena lokasi pengamatan siswa yang berbedabeda. (3) Siswa ada yang belum dapat mengajukan pertanyaan dan memberi komentar jawaban (> $70 \%)$.

Rekomendasi untuk pembelajaran selanjutnya (siklus 2) adalah guru di sarankan (1) memanajemen waktu dengan baik agar semua kelompok dapat dibimbing walaupun siswa bekerja pada kelompok dengan lokasi yang berbeda-beda, (2) guru disarankan 
agar memberikan penguatan setelah siswa melakukan presentasi.

2. Siklus II

\section{a. Perencanaan Siklus II}

Siklus 2 materi perkembangbiakan pada makhluk hidup. Kompetensi dasar pada pembelajaran ini: mengidentifikasi kelangsungan hidup organisme melalui adaptasi, seleksi alam dan perkembangbiakan. Perencanaan tindakan pada siklus II dilakukan dengan mempersiapkan RPP model pembelajaran kooperatif dengan metode outdoor learning, serta menyusun lembar kerja siswa, lembar observasi aktivitas siswa dan lembar observasi guru.

b. Pelaksanaan Tindakan Siklus II Pelaksanaan tindakan

dilakukan tanggal 20 September 2014 dalam 1 kali pertemuan selama 2 x40 menit. Fase 1 Guru menyampaikan salam dan mempersiapkan siswa belajar dengan mengatur tempat duduk serta mengecek kehadiran siswa. Guru memberikan apersepsi dengan menanyakan kepada siswa "bagaimanakah cara makluk hidup mempertahankan hidup agar tidak punah selain dengan cara adaptasi?" (siswa diarahkan untuk menjawab reproduksi/ berkembangbiak)

Guru menyampaikan tujuan pembelajaran dan memotivasi siswa.

Fase 2 menyajikan informasi. Guru menyajikan informasi secara garis besar materi adaptasi pada makhluk hidup. Fase 3 membentuk kelompok belajar (1 kelompok 4-5 orang), membagikan LKS untuk masing- masing kelompok. Fase 4 membimbing kelompok belajar. Guru mengajak siswa ke luar kelas yaitu halaman sekolah dan sekitarnya untuk melakukan pengamatan. Siswa melakukan pengamatan pada hewan dan tumbuhan yang di temui di lapangan. Guru membimbing siswa dalam mengerjakan LKS. Siswa mendiskusikan hasil pengamatan. Setelah selesai pengamatan siswa kembali ke kelas. Guru membimbing siswa untuk mengkaji literatur (buku siswa). Fase 5 evaluasi. Siswa menyampaikan mempresentasikan hasil diskusi dan guru memberikan penguatan. Fase 6 memberikan penghargaan, guru memberikan penghargaan melalui pujian atau tepuk tangan. Selanjutnya, kegiatan penutup.

c. Observasi Siklus II

Pada proses pembelajaran berlangsung, pengamatan dilakukan oleh satu orang pengamat. Pengamatan dilakukan terhadap aktivitas siswa dan guru.

Tabel 3. Persentase aktivitas siswa siklus 2.

\begin{tabular}{clc}
\hline No & $\begin{array}{l}\text { Aspek Pengamatan } \\
\text { Aktivitas }\end{array}$ & $\begin{array}{c}\text { Siklus 2 } \\
(\%)\end{array}$ \\
\hline 1 & $\begin{array}{l}\text { Mengajukan } \\
\text { pertanyaan }\end{array}$ & 75,75 \\
\hline & $\begin{array}{l}\text { Turut memberi } \\
\text { komentar/ pendapat } \\
\text { atas jawaban/ } \\
\text { pertanyaan teman }\end{array}$ & 100 \\
\hline 3 & $\begin{array}{l}\text { Mencatat hasil } \\
\text { pengamatan pada } \\
\text { LKS }\end{array}$ & 100 \\
\hline 4 & $\begin{array}{l}\text { Melakukan } \\
\text { pengamatan }\end{array}$ & 100 \\
\hline
\end{tabular}

Hasil observasi aktivitas siswa pada Siklus II menunjukkan semua 
siswa $(100 \%)$ aktif (sudah melebihi indikator kinerja). Hasil observasi aktivitas siswa per aspek, dapat dilihat pada Tabel 3. Ada tiga aspek aktivitas yang sudah mencapai $100 \%$ yaitu memberi komentar/pendapat atas jawaban/ pertanyaan teman dan mencatat hasil pengamatan pada LKS, disusul dengan aktivitas bertanya $75,75 \%$.

d. Refleksi Siklus II

Temuan-temuan pada siklus II: (1) Guru sudah melakukan penguatan setelah siswa mempresentasikan hasil diskusi, (2) Dalam membimbing kelompok diskusi, guru sudah memantau proses pembelajaran di luar kelas dengan lokasi pengamatan siswa yang berbedabeda, (3) Siswa sudah dapat mengajukan pertanyaan dan memberi komentar atau jawaban. Hanya 25\% siswa yang belum mengajukan pertanyaan. Keterlaksanaan pembelajaran semua tahapan sudah di lakukan.

Perbandingan aktivitas siswa pada Siklus 1 dan Siklus 2 menunjukkan ada peningkatan sebesar 72,73\%. Perbandingan hasil observasi aktivitas per aspek pada Siklus 1 dan Siklus 2 dapat dilihat pada Tabel 4.

Tabel 4. Perbandingan Aktivitas Siswa Siklus 1 dan Siklus 2 tiap aspek.

\begin{tabular}{clcc}
\hline No & \multicolumn{1}{c}{ Aspek pengamatan aktivitas } & Siklus 1 & Siklus 2 \\
\hline 1 & Mengajukan pertanyaan & 24,24 & 75,75 \\
\hline 2 & $\begin{array}{l}\text { Turut memberi komentar/ pendapat } \\
\text { atas jawaban/ pertanyaan teman }\end{array}$ & 24,24 & 100 \\
\hline 3 & Mencatat hasil pengamatan pada LKS & 81,81 & 100 \\
\hline 4 & Melakukan pengamatan & 100 & 100 \\
\hline
\end{tabular}

Pada akhir Siklus 2 keaktifan siswa sudah mencapai 100. Peningkatannya sebesar $72,73 \%$, indikator kinerja tercapai. Keterlaksanaan proses pembelajaran juga mencapai $100 \%$. Pembelajaran dengan menerapkan model kooperatif disertai metode outdoor learning pada proses pembelajaran dapat meningkatkan beberapa aspek yaitu mengajukan pertanyaan, turut memberi komentar/ jawaban, melakukan pengamatan dan mengerjakan tugas.

Pada aspek 2 semua siswa $100 \%$ memberikan komentar atas jawaban/ pertanyaan teman. Ada peningkatan lebih dari $70 \%$ yaitu sebanyak $75 \%$. Kegiatan pengamatan di laur kelas membuat siswa dapat mengamati secara langsung objek pengamatan, sehingga memperoleh pengalaman belajar secara langsung. Kegiatan ini membangkitkan rasa ingin tahu siswa ditunjukkan dengan aktivitas bertanya. Pertanyaan yang diajukan siswa terkait pertanyaanpertanyaan berupa fakta yang terkait hasil pengamatan. Selain itu juga siswa mengajukan pertanyaan pada saat siswa melakukan diskusi dan presentasi mengenai hasil pengamatan.

Pada Siklus 1 aktivitas siswa, masih terdapat beberapa pertanyaan yang tidak dikerjakan siswa. Namun, pada Siklus 2 semua pertanyaan dalam LKS sudah dijawab. Peningkatan aktivitas siswa dalam memberikan pendapat atau komentar 
dari jawaban atau pertanyaan teman ini terjadi pada saat siswa berdiskusi dalam kelompok atau antar kelompok pada saat presentasi. Diskusi yang tampak antar anggota kelompok pada saat siswa mengamati, mencatat dan membahas hasil pengamatan serta menjawab pertanyaan-pertanyaan pada LKS. Siswa saling bertukar pendapat sehingga untuk mencapai kesepakatan bersama dalam anggota kelompok siswa mengemukakan pendapat dan mengomentari pendapat anggota kelompoknya. Pembelajaran dengan menggunakan model kooperatif melatih kerjasama antar siswa dan melatih keterampilan komunikasi siswa.

Aspek pengamatan yang ketiga yaitu mencatat hasil pengamatan pada LKS. Pada Siklus 1 siswa mengamati bentuk-bentuk adaptasi, berdasarkan hasil pengamatan siswa sudah dapat menemukan bentuk-bentuk adaptasi morfologi. Pada Siklus 2 siswa mengamati bentuk-bentuk perkembangbiakan pada makhluk hidup, baik pada tumbuhan maupun hewan yang dijumpai di halaman sekolah dan sekitar sekolah. Berdasarkan hasil LKS, siswa juga mengumpulkan data dari studi literatur untuk melengkapi hasil pengamatan dari luar kelas. Hasil pengamatan siswa dicatat dalam tabel pengamatan. Mencatat hasil pengamatan dalam tabel melatih siswa untuk mengorganisasi hasil pengamatan sesuai dengan ciri khusus yang terdapat pada makhluk hidup. Keterampilan siswa mencatat hasil pengamatan pada Siklus 1 hanya $80 \%$, masih terdapat $20 \%$ siswa yang belum mencatat hasil pengamatan. Hal ini terkait dengan pembagian tugas dalam kelompok. Namun, pada
Siklus 2 pembagian tugas dalam kelompok belajar siswa sudah merata sehingga semua anggota kelompok mencatat hasil pengamatannya masing-masing dalam LKS.

Pada kegiatan pembelajaran Siklus 1 dan Siklus 2 semua siswa sudah melakukan pengamatan. Siswa mengamati dengan melihat objek secara langsung pada objek. Pengamatan dilakukan dengan melihat langsung objek tumbuhan dan hewan selain itu juga pengamatan dilakukan dengan studi literatur. Pengamatan yang dilakukan siswa pada Siklus 1 pada bentuk-bentuk adaptasi, siswa mengamati bentuk adaptasi morfologi pada tumbuhan yang ada di sekitar, belum dapat melihat adaptasi pada hewan karena tidak dijumpai di halaman sekitar sekolah. Pengamatan siswa pada Siklus 2 pada bentuk-bentuk reproduksi makhluk hidup siswa sudah dapat mengamati secara langsung objek tumbuhan dan hewan dengan studi literatur. Aktivitas ini melibatkan aktivitas mental siswa karena membutuhkan pengetahuan siswa dalam mengidentifikasi sesuai ciri pada tumbuhan dan hewan. konsep interaksi antara siswa dan alam terbuka. Menurut Sa'adah (2011) hal tersebut diyakini dapat memberikan suasana yang kondusif untuk membentuk sikap, cara berfikir serta persepsi yang kreatif dan positif dari setiap siswa.

\section{Simpulan dan Saran}

1. Terjadi peningkatan aktivitas belajar siswa sebesar $72,73 \%$.

2. Proses pembelajaran menggunakan model pembelajaran kooperatif disertai metode outdoor learning, terlaksana $100 \%$. 
61 Jurnal Pendidikan Matematika dan IPA Vol. 5. No. 1. Januari 2014: 54-61

\section{Daftar Pustaka}

Husamah. 2013. Pembelajaran Luar Kelas Outdoor Learning. Jakarta : Prestasi Pustaka.

Kunandar. 2011. Langkah Mudah Penelitian Tindakan Kelas Sebagai Pengembangan

Profesi Guru. Jakarta: PT Rajawali Press.

Kementerian Pendidikan dan Kebudayaan. 2013. Buku Guru Ilmu Pengetahuan Alam Kelas VIII. Jakarta: Kementerian Pendidikan dan Kebudayaan.

Lie, A. 2002. Cooperative Learning Mempraktekan Kooperatif Learning di Ruang-ruang Kelas. Jakarta: Grafindo.

Miles, MB \& Huberman, AM. 2009. Analisis Data Kualitatif: Buku Sumber Tentang MetodeMetode Baru (Penerjemah: Tjetjep, R.A). Jakarta: UI Press.
Nawawi, R, Asri A, Sunarti S.E. 2013. Pengaruh Penerapan Metode Outdoor Learning Terhadap Minat Belajar Siswa Pokok Bahasan Lingkungan Hidup. Jurnal KIM Fakultas Matematika dan IPA Vol 1 No 1. http://kim.ung.ac.id/index.php /KIMFMIPA/article/download /3670/3646

Sa'adah, F.U. 2011. Pembelajaran IPA SD Berorientasi Outdoor Learning.

(Online)(http://www.google.co $\mathrm{m} / \mathrm{search}$ ?hl=id\&source $=\mathrm{hp} \& \mathrm{q}=$ makalah+pembelajaran+IPA+S $\mathrm{D}+$ berorientasi+Oudoor+Learni ng).

Sudjana, N. 2006. Penilaian Proses dan Hasil Belajar Mengajar. Bandung: Remaja Rosdakarya.

Vera, A. 2012. Metode Mengajar Anak di Luar Kelas (Outdoor Study). Yogyakarta : Diva Press. 